\title{
Coqueluche: \\ tratamiento y complicaciones
}

DR, ANTONIO BANFI * $\mathbf{y}^{* *}$.

"Recientemente se ha hablado de la eficacia del empleo del suero de convalescientes de Coqueluche y de una preparación etérea con desgarro de enfermos, propuesta por Krauss", esto aparecía en 1916 en el Semanario Médico Alemán (1). Finkelstein (2) señalaba: "las inyecciones de éter me parecen ineficaces pero, con los preparados de quinina creo haber observado alivio de los accesos y una menor duración de la enfermedad". Chalamel en 1917 (3), indicaba la eficacia de la carrera en automóvil descubierto; Nobécourt (3) atribuía gran éxito a los baños de aire comprimido. $\mathrm{Y}$ así como éstas hay numerosas comunicaciones que expresan la utilidad en la Coqueluche, de tratamiento tales como: el vuelo en avión $(4,5)$; la luz ultravioleta; la vacunación con Bordetellas vivas (6); el extracto de vesícula biliar de buey; la "medicina de hierbas chinas" y la hemoterapia.

La tos convulsiva continúa representando uno de los grandes problemas terapéuticos. Se ha avanzado enormemente en el control de la enfermedad pero una vez que ésta se hace manifiesta, es decir, el paciente entra en la fase paroxística o espasmódica, todo tratamiento actualmente conocido y aceptado resulta muy desilusionante.

El tratamiento de la Coqueluche desde la iniciación de la era antibiótica se ha dividido en un tratamiento general y un tratamiento antimicrobiano; los aspectos que además revisamos, comprenden la inmunización pasiva, las complicaciones y la sugerencia de algunos posibles avances, Tabla № 1. El tratamiento general, Tabla № 2, desde antes que se definiera la naturaleza contagiosa de la enfermedad ha contemplado el

\footnotetext{
* Hospital Luis Calvo Mackenna.

** Unidad de Microbiología, Area Oriente. Univ, de Chile.
}

T A B L A $\quad \mathrm{N}: 1$

COQUELUCHE. TRATAMIENTO

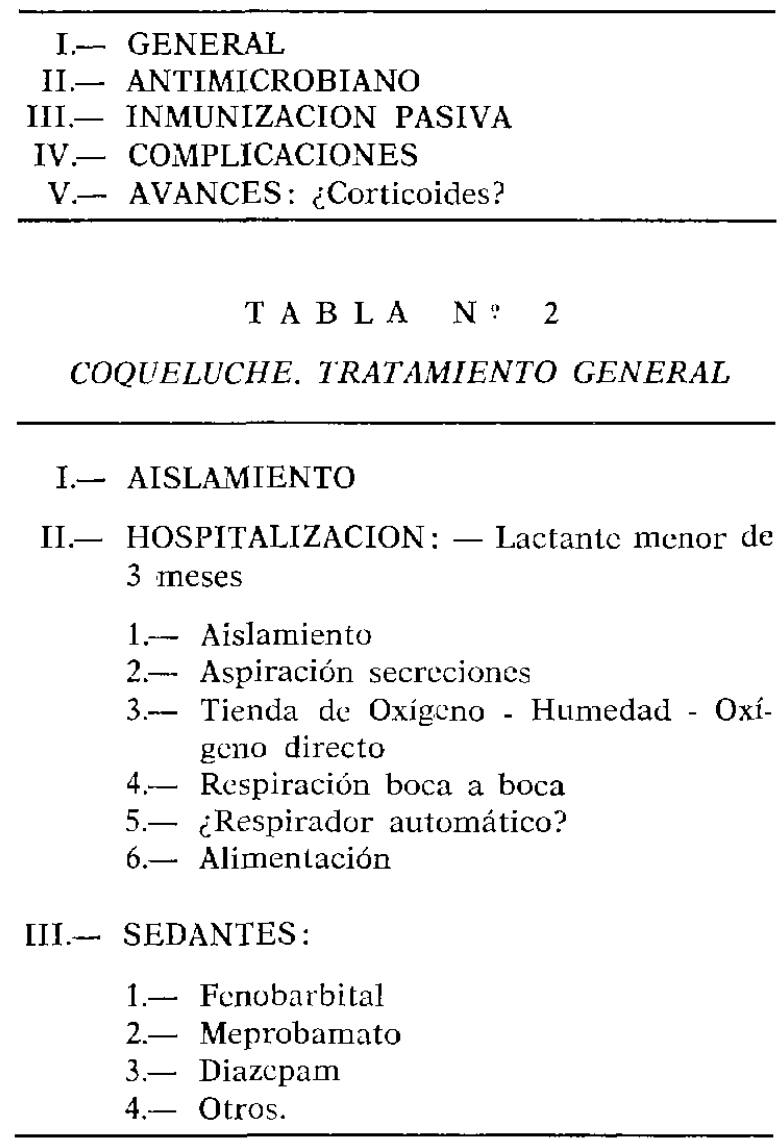

aislamiento. En nuestro medio y debido a las condiciones de la vida moderna este primer aspecto resulta muchas veces impracticable. En el niño mayor y en aquel en que el curso de la enfermedad es moderado o 
benigno resulta poco práctico aislarlos. En estos pacientes las únicas medidas posibles son las antimicrobianas.

La hospitalización es un aspecto impor. tante especialmente en el lactante menor de 3 meses, este niño es el que presenta habitualmente las formas evolutivas más severas de Coqueluche y las crisis de apnea son más frecuentes. La hospitalización implica aislamiento en un servicio de enfermedades infecciosas con todos los elementos de técnicas específicas.

La aspiración de secreciones es también necesaria pues la acumulación de ellas y su espesamiento intensifican el curso de la enfermedad y favorecen la aparición de complicaciones.

El uso de la tienda de $\mathrm{O}_{2}$ con una concentración y humedad adecuadas son elementos de indiscutible alivio para el niño. El $\mathrm{O}_{2}$ directo es necesario en la reanimación y en la recuperación de crisis de tos prolongada y que determinan la aparición de cianosis.

Cuando un lactante presenta un paro respiratorio, la respiración boca a boca está indicada y es consenso que es la única acción que puede salvar la vida. El empleo de los respiradores automáticos para proporcionar respiración asistida no ha sido probado en forma amplia como para proponer su uso habitual; será necesario ensayar este tipo de equipo para determinar su posible eficacia.

Uno de los problemas generales más importantes que plantea la Coqueluche es la alimentación; es decisiva la observación cuidadosa de la forma de alimentarse del lactante y la relación ingestión y accesos. Los accidentes de aspiración pueden ser fatales.

Desde hace muchos años (7), se ha propuesto el uso de drogas sedantes puesto que se ha visto una relación clínica entre la frecuencia e intensidad de los accesos de tos y la alteración síquica que provocan en el niño. Se han empleado el Fenobarbital, Meprobamato y otras; últimamente el Diazepam y la Tioridazina. Todos los resultados no son concluyentes pues la evaluación de un problema complejo ( tos - alteración síquica), es extremadamente difícil. En todo caso estas observaciones, no controladas, senalan cierta utilidad de la sedación de estos pacientes.

El tratamiento antimicrobiano de la Coqueluche está dirigido a la erradicación nasofaríngea de la Bordetella pertussis. Diversos estudios muestran que esta terapéutica no modifica el curso de la enfermedad cuan- do se instituye en la etapa paroxística y que tampoco previene las complicaciones $(8,9)$. Existen pruebas concluyentes (10), de que la Eritromicina es la droga más eficaz en el tratamiento antimicrobiano; los niveles que alcanza son activos frente a la Bordetella y logra eliminarla en un plazo de tres a cuatro días. La Ampicilina es también un antibiótico eficaz aunque los estudios señalan que demoraría un poco más en obtenerse la erradicación faríngea de la Bordetella; el Cloramfenicol ha sido ensayado desde hace muchos años y se conoce su acción sobre el germen; en nuestro medio, y dados los riesgos potenciales que encierra la droga, representa una tercera alternativa terapéutica.

La inmunización pasiva en el tratamiento de la Coqueluche y en la prevención de los contactos susceptibles se ha propuesto desde hace mucho tiempo. Bradford en 1935 (11), revisó el problema desde el comienzo de este siglo y junto con su propia experiencia concluyó que el empleo de sueros del convalescientes o la hemoterapia tenían escasos o ningún valor cuando se administraba en el período catarral o en el paroxístico. Con el desarrollo posterior de la inmunoglobulina específica antipertussis se creyó obtener un valioso elemento terapéutico. Proliferaron los estudios de pacientes tratados con inmunoglobulina y hasta 1970 prácticamente la mayoría de ellos señalaba la eficacia de su empleo $(12,13)$, sin embargo muy pocas de estas experiencias habian sido estudios controlados. En un trabajo realizado en Chicago entre 1968-69 (14) se empleó la inmunoglobulina específica antipertussis en niños en la primera semana del período espasmódico. Se les administró $21 / 2 \mathrm{cc}$ de inmunoglobulina y no se observó diferencia en relación con el grupo control en cuanto a: frecuencia de las crisis de tos, apnea, vómitos y complicaciones pulmonares. En el Hospital Luis Calvo Mackenna entre 1971-74 se han tratado con inmunoglobulina específica 104 niños con tos convulsiva, las dosis totales correspondieron a 2 y $4 \mathrm{cc}$. La gran mayoría de los niños se encontraba en la parte final de la fase catarral o comienzo del período paroxístico. No se observó ninguna diferencia respecto de los niños que no recibieron inmunoglobulina específica en cuanto a: la frecuencia de la crisis de tos, apnea y los días de hospitalización. Pareciera pues que existen suficientes evidencias en cuanto a no recomendar el uso de la inmunoglobulina específica en la etapa catarral y menos en la espasmódica de la enfermedad.

La conducta a seguir con los contactos, Tabla № 3, es revacunar aquéllos con inmu- 
T A B L A $\mathrm{N}: 3$

COQUELUCHE. CONTACTOS

\section{I.- CON INMUNIZACION PREVIA:}

- Revacunar

II.- SIN INMUNIZACION PREVIA:

- Inmunoglobulina específica (preferentemente en menor de 3 meses)

T A B L A $\mathrm{N}: 4$ $1973-1974$

COQUELUCHE. COMPLICACIONES

Hospitales: Arriarán, C. Mackenna, Ex. G. Cortés: 278

I.- RESPIRATORIAS :

1.- Bronconeumonía 48

2.- Bronquitis Bronquiolitis 25

3.- Neumonitis 14

4.- Atelectasia

5.- Neumotórax

II.- SISTEMA NERVIOSO CENTRAL:

Encefalopatía

III.- OTRAS :

Diarrea intrahospitalaria

Septicemia Gram negativo

nización previa, menores de 4 años, y utilizar la inmunoglobulina específica en los contactos sin inmunización previa y preferentemente en el niño menor de 3 meses.

\section{COMPLICACIONES}

Las principales complicaciones, Tabla $\mathrm{N}^{\circ}$ 4, de la tos convulsiva son las respiratorias y las más frecuentes de ellas son la bronconeumonía, bronquitis, bronquiolitis, neumonitis y atelectasias residuales. La frecuencia con que se presentan estas complicaciones respiratorias es muy variable según distintos autores. Fawcett (15), observó en 566 niños con Coqueluche un $26 \%$ de atelectasias y un $48 \%$ de bronconeumonía, bronquitis y neumonitis. En un periodo de 18 meses

entre 1973 y septiembre 1974, de un total de 278 casos de Coqueluche, de los hospitales Arriarán, Calvo Mackenna y Exequiel González Cortés, la bronconeumonía se presentó en un $17 \%$ de los niños siendo la causa más freruente de complicación respiratoria.

La complicación del sistema nervioso central denominada encefalopatía coqueluchosa es felizmente poco frecuente y en los casos de los hospitales antes citados sólo se observó en 4 pacientes. El tratamiento de las complicaciones es a veces muy difícil puesto que los problemas respiratorios son causados por gérmenes propios de infecciones intrahospitalarias.

\section{AVANCES}

Uno de los más novedosos tratamientos propuestos para la tos convulsiva ha sido el empleo de Corticoides. De acuerdo con los conceptos actuales acerca de la fisiopatología de la tos en la Coqueluche, esto es, Iesiones inflamatorias del tracto respiratorio y asociación con un posible efecto antígeno anticuerpo sobre el centro de la tos, unos autores griegos ensayaron el empleo de Corticoides en la Coqueluche (16). Sus pacientes estaban en la primera semana de la fase paroxística y los accesos de tos y apnea y los vómitos fueron menos frecuentes que en el grupo control. Al mismo tiempo la enfermedad fue más corta en los niños menores de 1 año; los autores sugieren que los corticoides administrados en el comienzo de la fase paroxística pueden tener un efecto beneficioso pero, al mismo tiempo recomiendan que su uso debe estar limitado a los casos severos. Si bien es cierto que éste es un avancse novedoso, será necesario verificar este estudio en enfermos con Coqueluche comprobada bacteriológicamente.

De todo lo expuesto resulta claro que hemos avanzado muy poco en el tratamiento de la Coqueluche y en el conocimiento de los padres se mantiene vigente la supuesta eficacia de medidas tales como el vuelo en avión. Es entonces en el control de la enfermedad donde debe estar puesto nuestro énfasis y los posibles progresos terapéuticos tendrán que surgir de los nuevos adelantos que aporten la bacteriología, fisiopatología, inmunología y farmacología.

\section{REFERENCIAS}

1.- Krauss, R.- Semanario Médico Alemán. 10, 1916. 
2.- Finkelstein, H.- Tratado de las enfermedades del niño de pecho. 3" Edición, 1929.

3.- Laffont, A.; Durieux, A.- Encyclopédie Médico-Chirurgicale, Maladies Infectienses, $2^{\text {? }}$ ed., fas. 8017 C, 11-a, 1947.

4.- Levent, R.- La Méthode de Matter de Strasbourg dans le traitment de la Coqueluche. Gnz. Hosp., 8: 121-122, 1947.

5.- Evrard, S., Simon, A.- Un cas grave de Coqueluche traité par le vol en avión. Brux. Méd. 12: 650-654, 1947.

6.- Nicolle, C.; Conor, A.- Vacuna viva en brote de Coqueluche en Túnez. CR. Acad. Sci., París, 156: 1849, 1913.

7.- Czerny, A.- Lecciones Clínicas de Pediatría. Ed. Pubal. Barcelona, 1944.

8.- Hazen, L.N.; Jackson, G.G.; Chang, S.M.; Place, E.H.; Finland, M.- Antibiotic Treatment of Pertussis, J. Pediat. 39: 1, 1951.

9.-Weinstein, L.; Saltser, R.; Marrow, C.T.The treatment of pertussis with aureomycin, chloramphenicol and terramycin, J.. Pediat. 39: 549, 1951.
10.- Bass, J.W.; Klenk, E.; Kotheimer, J.; Linnemann, C.O.; Smith, M.; Mitchell, I.; Coner, E.; Leidermann, D.- Antimicrobial treatment of pertussis, The J. of Ped. 75 : 768-781, 1969.

11.- Bradford, W.L.- Use of convalescent blood in whooping cough - with a review of the literature. Amer. J. Dis, Child. 50: 918, 1935.

12.- Lapin, J.H.- Serum in the prophylaxis of contacts and the teatment of whooping cough. J. Pediat. 26: 555, 1946.

13.- Kohn, J.L.; Rudel, G.H.; Weischel, M.; Buxbaum, L- Hyper - inmune serums in the treatment of whooping cough. Amer. J. Dis. Child. 74: 321, 1947.

14.- Balagtas, R.; Nelson, K.; Levin, S.; Gottof, S.- Treatment of Pertussis with pertussis inmune globulin. Pediatrics, 79 : 203-208, 1971.

15.- Fawcett, J.; Parry, H.E.- Lung changes in pertussis and measles in childhood. Brit. $J$. Radiol., 30: 76, 1957.

16.- Zoumboulakis, D.; Anagnostakis, D.; Albanis, V.; Matsaniotis, N.- Steroids in treatment of pertussis. Arch. Dis. Child., 48: 5154, 1973. 